\title{
PTHrP and breast cancer: more than hypercalcemia and bone metastases
}

\author{
Kata Boras-Granic and John J Wysolmerski*
}

\begin{abstract}
Parathyroid hormone-related protein (PTHrP) causes hypercalcemia in cancer patients. PTHrP is required for normal breast development and has been shown to promote bone metastases from breast cancers. However, whether the protein also contributes to the formation of primary tumors has been unclear. Two recent papers suggest it may. First, a report in Nature Genetics identified the PTHrP locus as a new breast cancer susceptibility gene. Second, a paper in Journal of Clinical Investigation demonstrated that PTHrP promotes tumor growth and metastases in MMTV-PyMT mice. These studies implicate PTHrP in the development and growth of primary breast tumors and underscore the need for further research.
\end{abstract}

\section{Background}

Parathyroid hormone-related protein (PTHrP) - also parathyroid-like hormone (PTHLH) - was discovered as the cause of a common paraneoplastic syndrome, humoral hypercalcemia of malignancy $[1,2]$. Both the PTHLH and parathyroid hormone genes descended from a common ancestor and both proteins bind and activate the same Gprotein coupled receptor (type $1 \mathrm{PTH} / \mathrm{PTHrP}$ receptor). PTHrP is widely expressed in embryos and contributes to the development of many organs, including the breast $[1,2]$. PTHrP is produced by epithelial cells in the embryonic mammary bud, and the type $1 \mathrm{PTH} / \mathrm{PTHrP}$ receptor is expressed by the surrounding mesenchyme. Genetic disruption of either gene results in a failure of mammary development in mice and humans [2]. In the adult virgin breast, PTHrP is produced by myoepithelial cells and its receptor is expressed in the periductal stroma $[2,3]$. Overexpression of PTHrP in myoepithelial cells

*Correspondence: john.wysolmerski@yale.edu

Section of Endocrinology and Metabolism, Department of Internal Medicine, Yale University School of Medicine, TAC S131, Box 208020, New Haven, CT 06520-8020, USA inhibits ductal extension, but postnatal disruption of the PTHLH gene in these cells has no effect [3]. During lactation, PTHrP is produced by alveolar epithelial cells and is secreted into milk and into the maternal circulation, where it participates in the mobilization of skeletal calcium for milk production [4]. PTHrP thus has important functions in normal breast development and physiology.

PTHrP also contributes to the pathophysiology of breast cancer. PTHrP production by tumor cells in the bone microenvironment has been shown to promote osteoclastic activity and contribute to osteolytic bone metastases [5]. The question of PTHrP's function in primary tumors has been less clear. Studies in cultured breast cancer cell lines have reported conflicting effects on tumor cell behavior [6,7]. Clinical studies have also shown disparate results; some smaller case series suggest that PTHrP expression predicts more aggressive behavior $[8,9]$, while a large, well-controlled clinical study from Melbourne suggested that PTHrP expression was an independent predictor of a more benign clinical course [10]. Therefore, while PTHrP's participation in the development of bone metastases has been well established, what effects, if any, PTHrP has on the development or progression of primary tumors remained unclear. Now, two recent articles underscore the importance of PTHrP in primary breast cancers and call attention to the need for more studies to clarify the protein's functions in breast cancer biology.

\section{The articles}

First, in a recent paper published in Nature Genetics, Ghoussaini and colleagues combined several datasets encompassing 70,000 patients and 68,000 controls in order to perform genome-wide association studies to identify new breast cancer susceptibility loci [11]. One of the three new loci they identified, rs10771399, was in a $300 \mathrm{~kb}$ linkage disequilibrium block that contains only one gene, PTHLH.

Second, in work recently published in the Journal of Clinical Investigation, $\mathrm{Li}$ and colleagues examined the role of PTHrP expression in an animal model of breast cancer caused by PyMT [12]. The authors used the 
MMTV-Cre transgene to target the PTHLH gene in mammary epithelial cells, and found that while loss of PTHrP expression did not affect tumor incidence, it did dramatically prolong tumor latency, slow tumor growth and reduce metastases. Restraint of tumor growth correlated with reduced proliferation and increased apoptosis, perhaps due to alterations in cyclin $\mathrm{D}_{1}$, protein kinase $\mathrm{B} 1$ and 2 , and B-cell lymphoma 2 expression. The reduction in metastases may have been related to reductions in the expression of CXC chemokine receptor 4 and the inhibition of angiogenesis. Finally, the authors developed a blocking antibody to PTHrP and demonstrated that it could inhibit primary tumor growth and lung metastases in a xenograft model. These data suggest that PTHrP powerfully promotes tumor formation in breast cancer.

\section{Discussion}

The report from Ghoussaini and colleagues focuses attention on PTHrP as a potential contributor to breast cancer susceptibility. If the PTHLH gene is confirmed to be causal in resequencing studies of the rs10771399 locus, then animal studies such as those described by $\mathrm{Li}$ and colleagues will be instrumental in understanding how PTHrP might alter disease susceptibility. Together, these two studies raise many interesting questions regarding the mechanisms by which PTHrP might alter the formation or progression of breast tumors. Perhaps the most perplexing involves the opposite results reported in a similar study by Fleming and colleagues demonstrating that disruption of the PTHrP gene increased the incidence of tumors in MMTV-Neu mice, results consistent with the clinical study from Australia $[10,13]$. The opposing results of these two transgenic mouse studies highlight an important issue for future research.

Clearly, the molecular context appears to be critical for determining PTHrP's actions. Although both MMTVNeu and MMTV-PyMT are models of luminal-type cancer, their pathways to transformation vary in important ways, and other molecules also exert differing effects on tumor formation in these two strains $[14,15]$. Sorting out why PTHrP has opposite effects in these two models will probably provide important clues to understanding the molecular nature of its actions in breast cancer.

\section{Abbreviations}

MMTV, mouse mammary tumor virus; Neu, heregulin 2 gene; PTHLH, parathyroid-like hormone; PTHrP, parathyroid hormone-related protein; PyMT, polynoma middle T antigen.
Competing interests

The authors declare that they have no competing interests.

Published: 25 April 2012

\section{References}

1. Strewler GJ: The physiology of parathyroid hormone-related protein. NEng/ J Med 2000, 342:177-185.

2. Wysolmerski J: Parathyroid hormone-related protein. In Primer on the Metabolic Bone Diseases and Disorders of Mineral Metabolism. Edited by Rosen C. 7th edition. Washington, DC: American Society for Bone and Mineral Research; 2008:127-133.

3. Boras-Granic K, VanHouten J, Hiremath M, Wysolmerski J: Parathyroid hormone-related protein is not required for normal ductal or alveolar development in the post-natal mammary gland. PLoS One 2011, 6:e27278.

4. VanHouten JN, Dann P, Stewart AF, Watson CJ, Pollak M, Karaplis AC, Wysolmerski JJ: Mammary-specific deletion of parathyroid hormonerelated protein preserves bone mass during lactation. J Clin Invest 2003, 112:1429-1436.

5. Akhtari M, Mansuri J, Newman KA, Guise TM, Seth P: Biology of breast cancer bone metastasis. Cancer Biol Ther 2008, 7:3-9.

6. Shen X, Qian L, Falzon M: PTH-related protein enhances MCF-7 breast cancer cell adhesion, migration, and invasion via an intracrine pathway. Exp Cell Res 2004, 294:420-433.

7. Luparello C, Sirchia R, Lo Sasso B: Midregion PTHrP regulates Rip1 and caspase expression in MDA-MB231 breast cancer cells. Breast Cancer Res Treat 2008, 111:461-474.

8. Bundred NJ, Walker RA, Ratcliffe WA, Warwick J, Morrison JM, Ratcliffe JG: Parathyroid hormone related protein and skeletal morbidity in breast cancer. Eur J Cancer 1992, 28:690-692.

9. Hoey RP, Sanderson C, Iddon J, Brady G, Bundred NJ, Anderson NG: The parathyroid hormone-related protein receptor is expressed in breast cancer bone metastases and promotes autocrine proliferation in breast carcinoma cells. Br J Cancer 2003, 88:567-573.

10. Henderson MA, Danks JA, Slavin JL, Byrnes GB, Choong PF, Spillane JB, Hopper JL, Martin TJ: Parathyroid hormone-related protein localization in breast cancers predict improved prognosis. Cancer Res 2006, 66:2250-2256.

11. Ghoussaini M, Fletcher O, Michailidou K, Turnbull C, Schmidt MK, Dicks E, Dennis J, Wang Q, Humphreys MK, Luccarini C, Baynes C, Conroy D, Maranian M, Ahmed S, Driver K, Johnson N, Orr N, Dos Santos Silva I, Waisfisz Q, MeijersHeijboer H, Uitterlinden AG, Rivadeneira F; Netherlands Collaborative Group on Hereditary Breast and Ovarian Cancer (HEBON), et al:: Genome-wide association analysis identifies three new breast cancer susceptibility loci. Nat Genet 2012, 44:312-318.

12. Li J, Karaplis AC, Huang DC, Siegel PM, Camirand A, Yang XF, Muller WJ, Kremer R: PTHrP drives breast tumor initiation, progression, and metastasis in mice and is a potential therapy target. J Clin Invest 2011, 121:4655-4669.

13. Fleming NI, Trivett MK, George J, Slavin JL, Murray WK, Moseley JM, Anderson RL, Thomas DM: Parathyroid hormone-related protein protects against mammary tumor emergence and is associated with monocyte infiltration in ductal carcinoma in situ. Cancer Res 2009, 69:7473-7479.

14. Lim E, Wu D, Pal B, Bouras T, Asselin-Labat ML, Vaillant F, Yagita H, Lindeman GJ, Smyth GK, Visvader JE: Transcriptome analyses of mouse and human mammary cell subpopulations reveal multiple conserved genes and pathways. Breast Cancer Res 2010, 12:R21.

15. Prosperi JR, Khramtsov Al, Khramtsova GF, Goss KH: Apc mutation enhances PyMT-induced mammary tumorigenesis. PLoS One 2011, 6:e29339.

\section{doi:10.1186/bcr3129}

Cite this article as: Boras-Granic K, Wysolmerski Jj: PTHrP and breast cancer: more than hypercalcemia and bone metastases. Breast Cancer Research 2012, 14:307. 